\title{
The Importance of Having Arc: Expression of the Immediate-Early Gene Arc Is Required for Hippocampus- Dependent Fear Conditioning and Blocked by NMDA Receptor Antagonism
}

\author{
Jennifer Czerniawski, Fredrick Ree, Chester Chia, Kartik Ramamoorthi, Yayoi Kumata, and Timothy A. Otto \\ Department of Psychology, Rutgers University, Piscataway, New Jersey 08854
}

Long-lasting, experience-dependent changes in synaptic strength are widely thought to underlie the formation of memories. Many forms of learning-related plasticity are likely mediated by NMDA receptor activation and plasticity-related gene expression in brain areas thought to be important for learning and memory, including the hippocampus. Here, we examined the putative role of activity-regulated cytoskeletal-associated protein (Arc), an immediate-early gene (IEG) whose expression is tightly linked to the induction and maintenance of some forms of neuronal plasticity, in hippocampus-dependent and hippocampus-independent forms of learning. The extent to which learning-induced Arc expression may depend on NMDA receptor activation was also assessed. First, we observed an increase in Arc gene and protein products in both dorsal hippocampus $(\mathrm{DH})$ and ventral hippocampus $(\mathrm{VH})$ of male Sprague Dawley rats after hippocampusdependent trace and contextual fear conditioning, but not after hippocampus-independent delay fear conditioning. Specific knockdown of Arc using antisense oligodeoxynucleotides (ODNs) in DH or VH attenuated the learning-related expression of Arc protein, and resulted in a dramatic impairment in trace and contextual, but not delay, fear conditioning. Finally, pretraining infusions of the NMDA receptor antagonist APV into the $\mathrm{DH}$ or $\mathrm{VH}$ blocked the learning-induced enhancement of Arc in a regionally selective manner, suggesting that NMDA receptor activation and Arc translation are functionally coupled to support hippocampus-dependent memory for fear conditioning. Collectively these results provide the first evidence suggesting that NMDA receptor-dependent expression of the IEG Arc in both DH and VH likely underlies the consolidation of a variety of forms of hippocampus-dependent learning.

\section{Introduction}

Largely separate lines of emerging evidence suggest that NMDA receptor-mediated plasticity and immediate-early gene (IEG) activation may play important roles in the molecular cascades underlying acquisition and consolidation of a variety of forms of memory (Nakazawa et al., 2004; Miyashita et al., 2008). Specifically, there is now a wealth of data indicating that NMDA receptor activation is essential for the induction of some forms of synapse-specific plasticity [including long-term potentiation (LTP)] within both the hippocampus and amygdala, and that NMDA receptor antagonism impairs many forms of learning in a regionally dependent manner (Bliss et al., 2007). With respect to gene function, a number of IEGs that may be importantly involved in both synaptic plasticity and memory have now been identified (Guzowski, 2002). Among these, Arc (activityregulated cytoskeletal-associated protein) has received consider-

\footnotetext{
Received May 3, 2011; revised June 13, 2011; accepted June 17, 2011.

Author contributions: J.C., K.R., and T.A.O. designed research; J.C., F.R., C.C., K.R., Y.K., and T.A.O. performed research; J.C. and T.A.O. analyzed data; J.C., K.R., and T.A.O. wrote the paper.

This work was supported by National Science Foundation Grant IOS 0919159.

Correspondence should be addressed to Dr. Timothy A. Otto, Program in Behavioral Neuroscience, Department of Psychology, Rutgers University, 152 Frelinghuysen Road, Piscataway, NJ 08854. E-mail: totto@rci.rutgers.edu.

DOI:10.1523/JNEUROSCI.2211-11.2011

Copyright $\odot 2011$ the authors $\quad 0270-6474 / 11 / 3111200-08 \$ 15.00 / 0$
}

able recent attention (Bramham et al., 2010; Shepherd and Bear, 2011), in part because it is more tightly coupled to the induction of synaptic plasticity than to neuronal activity per se (Fletcher et al., 2006). Importantly, Arc is one of the only IEGs whose mRNA is rapidly transported to activated synaptic zones, where it undergoes local protein synthesis and associates with dendritic cytoskeletal proteins (Link et al., 1995; Lyford et al., 1995; Steward et al., 1998). Moreover, Arc expression in hippocampus is rapidly and robustly enhanced following a number of behavioral manipulations, including novel environment exploration and spatial learning (Guzowski et al., 2001; Kelly and Deadwyler, 2002; Fletcher et al., 2006), while inhibiting hippocampal Arc translation with antisense oligodeoxynucleotides (ODNs) blocks both late-phase LTP and the consolidation of some forms of memory in both the hippocampus and amygdala (Guzowski et al., 2000; Ploski et al., 2008); similar patterns of physiological and behavioral data are observed in Arc knock-out mice (Plath et al., 2006).

Collectively, the data reviewed above suggest that both NMDA receptor activation and Arc expression are essential to the functional and structural modifications that lead to selective, long-lasting, synapse-specific alterations of synaptic efficacy and, in turn, some forms of memory. However, while there is suggestive evidence that Arc expression and NMDA receptor activation may be interdependent in vitro (Link et al., 1995; Lyford et al., 
1995; Steward et al., 1998), the extent to which these events are interdependent in vivo and, together, function to subserve memory remains largely uncharacterized. In the present study we assessed whether hippocampus-dependent trace and contextual fear conditioning alter hippocampal Arc mRNA and protein levels, and whether blocking Arc translation would impair the acquisition and consolidation of hippocampus-dependent forms of fear conditioning. In an attempt to explore the potential interdependence between NMDA receptor activation and learning-induced Arc expression, we examined the effect of NMDA receptor antagonism on Arc protein levels induced by training. Finally, because we and others have previously observed a functional dissociation between dorsal hippocampus (DH) and ventral hippocampus (VH) (Moser and Moser, 1998; Yoon and Otto, 2007; Czerniawski et al., 2009), we directly compared the role of Arc in these subregions. Our results suggest that NMDA receptor-mediated Arc expression in both $\mathrm{DH}$ and $\mathrm{VH}$ contributes to the consolidation of emotional memories.

\section{Materials and Methods}

All procedures have been approved by Rutgers University's Institutional Animal Care and Use Committee.

\section{Subjects}

One hundred seventy-six naive male Sprague Dawley adult rats (Harlan) served as subjects. They were individually housed in plastic cages on a $12 \mathrm{~h}$ light/dark cycle with access to food and water ad libitum.

\section{Behavioral procedures}

Training. Trace fear conditioning was conducted $7-10 \mathrm{~d}$ after surgery. In our initial experiments examining Arc gene expression using quantitative PCR (qPCR) (Fig. 1), we used a trace conditioning paradigm identical to that used previously in our laboratory (Yoon and Otto, 2007; Czerniawski et al., 2009). Briefly, auditory trace fear conditioning took place in a single session consisting of 10 pairings of a tone conditioned stimulus (CS) $(20 \mathrm{~s}, 3.9 \mathrm{kHz}, 80 \mathrm{~dB})$ and footshock $(2 \mathrm{~s}, 0.6 \mathrm{~mA})$, with a trace interval of $30 \mathrm{~s}$ between the offset of the tone and onset of the shock. The first tone was presented after a 4 min acclimation period, and subsequent trials were separated by a $4 \mathrm{~min}$ intertrial interval (ITI). Thus, the total length of the training session was $49 \mathrm{~min}$. To shorten the total session length and thereby achieve greater temporal specificity of the effect of infusions of APV or Arc antisense ODNs, subsequent experiments used a trace conditioning paradigm consisting of 7 pairings of a tone CS $(16 \mathrm{~s}, 3.9 \mathrm{kHz}, 80 \mathrm{~dB})$ and footshock $(2 \mathrm{~s}, 0.6 \mathrm{~mA})$, with a trace interval of $28 \mathrm{~s}$ between the offset of the tone and onset of the shock. The first tone was presented after a $2 \mathrm{~min}$ acclimation period, and subsequent trials were separated by a 2 min ITI. As described below, both training paradigms resulted in robust acquisition of trace conditioning.

The parameters for delay fear conditioning were identical to those for trace conditioning, except that the trace interval was omitted and the CS and unconditioned stimulus (US) coterminated. While there is the possibility that ODN infusions into the $\mathrm{VH}$ could spread to the amygdala, and suggestive evidence that $\mathrm{VH}$ may participate in delay fear conditioning (Richmond et al., 1999; Maren and Holt, 2004), there is overwhelming evidence that $\mathrm{DH}$ does not participate in delay fear conditioning (Kim and Fanselow, 1992; Phillips and LeDoux, 1992; Misane et al., 2005; Wanisch et al., 2005). Thus, in the present experiment we administered Arc antisense ODNs into VH but not DH before delay fear conditioning. Prior studies have reported that Arc mRNA is increased following exposure to a novel context (Vazdarjanova et al., 2006); thus, in our initial experiments examining Arc gene expression using qPCR (Fig. 1), subjects were preexposed to the training chamber for $24 \mathrm{~h}$ before conditioning to reduce the salience of the context during conditioning. Finally, in these experiments, contextual conditioning was procedurally identical to both trace and delay conditioning except that the explicit auditory CS was never presented.

Testing. The testing session for trace or delay fear conditioning was conducted in a novel chamber $48 \mathrm{~h}$ after conditioning ( $24 \mathrm{~h}$ after context testing) in one session consisting of three trials that were procedurally identical to those used during training, except that the footshock US was not delivered. Freezing behavior, defined as a rigid posture and lack of movement except that required for respiration, was recorded throughout the entire testing session by an observer blind to the subjects' condition. These raw data were subsequently transformed into the percentage of time spent freezing during the ITI, CS, and trace interval, respectively. Conditioned fear to the training context was assessed $24 \mathrm{~h}$ after conditioning during a 6 min session in which the subject was returned to the chamber in which conditioning occurred. Neither the tone CS nor the footshock US were presented during this session.

\section{Surgery}

All subjects receiving cannula implantation surgery were first anesthetized with intraperitoneal administration of ketamine $(80 \mathrm{mg} / \mathrm{kg}$, Sigma)-xylazine (12 mg/kg,Sigma) mixture. Each subject's head was shaved, mounted in a stereotaxic apparatus (Kopf Instruments), and cleaned with alcohol and Betadine. Subcutaneous injections of Marcaine $(0.1 \mathrm{ml}, 25 \%$, Sigma $)$ in several locations below the scalp served as a local anesthetic and vasoconstrictor. The scalp was then incised and retracted. Six small burr holes were drilled into the skull. For subjects receiving infusions into $\mathrm{DH}$, guide cannulae (22 gauge, $11 \mathrm{~mm}$, PlasticsOne) were implanted bilaterally into the $\mathrm{DH}$ [anteroposterior (AP), $-3.8 \mathrm{~mm}$; mediolateral (ML), $\pm 2.5 \mathrm{~mm}$ from bregma; dorsoventral (DV), $-2.2 \mathrm{~mm}$ from dura]. For subjects receiving infusions into $\mathrm{VH}$, guide cannulae (22 gauge, $11 \mathrm{~mm}$, PlasticsOne) were implanted bilaterally into VH (AP, $-5.2 \mathrm{~mm}$; ML, $\pm 5 \mathrm{~mm}$ from bregma; $\mathrm{DV},-5.5 \mathrm{~mm}$ from dura). The cannulae were affixed with acrylic cement and anchored to the skull via four stainless steel screws. The incision was then closed with stainless steel surgical staples, and obdurators were placed into the guide cannula. All animals were closely monitored during the 7-10 d postsurgical recovery period. Subjects were randomly assigned to an infusion condition (see below) before behavioral training and testing.

\section{Oligodeoxynucleotide design, preparation, and infusion}

A subset of the subjects received infusions of antisense ODNs for Arc or scrambled ODNs, synthesized by Integrated DNA Technologies and obtained through the DNA Synthesis and Core Facility at University of Medicine and Dentistry of New Jersey (Piscataway, NJ). The ODNs were identical to those used previously (Guzowski et al., 2000; McIntyre et al., 2005; Ploski et al., 2008) and were prepared to encode antisense or scrambled sequences for Arc mRNA starting at the sequence near the translation start site. For the experimental group, base sets of 20 mer antisense ODNs with a sequence from bases 209 to 228 of the published Arc sequence were used. For the control group, the sequence was the same base composition in a randomized (scrambled) order. All ODNs were prepared using HPLC purification and then resuspended in aCSF at a concentration of $2 \mathrm{nmol} / \mu \mathrm{l}$.

The ODN infusions were administered via insertion of an infusion cannula into the guide cannula targeted at $\mathrm{DH}$ or $\mathrm{VH}$ at a rate of 0.25 $\mu \mathrm{l} / \mathrm{min}$. The infusion cannula protruded $1 \mathrm{~mm}$ beyond the tip of the guide cannula, and was connected via polyethylene tubing to a $10 \mu \mathrm{l}$ Hamilton syringe mounted in an infusion pump (Harvard Apparatus). A volume of $0.5 \mu \mathrm{l}(2 \mathrm{nmol} / \mu \mathrm{l})$ was infused bilaterally into either $\mathrm{DH}$ or $\mathrm{VH}$. The infusion cannula was replaced by the dummy cannula 2 min after the infusion was complete. Subjects were returned to their cages for $3 \mathrm{~h}$ before training; this delay between infusion and training was chosen based on prior data examining the time course and effectiveness of Arc ODN infusion (Guzowski et al., 2000; McIntyre et al., 2005). Subjects were infused with aCSF $3 \mathrm{~h}$ before both the context and tone testing sessions 24 and 48 h later, respectively (Fig. 1c).

\section{APV preparation and infusion}

A subset of the subjects received microinfusions of either aCSF (Harvard Apparatus) or APV (10 $\mu \mathrm{g} / \mu \mathrm{l}, \mathrm{pH} 7.4$ Sigma) dissolved in aCSF. The infusions were administered via insertion of an infusion cannula into the guide cannula targeted at $\mathrm{DH}$ or $\mathrm{VH}$ in the same manner as the ODNs described above. A volume of $0.5 \mu \mathrm{l}(0.25 \mu \mathrm{l} / \mathrm{min})$ was infused bilaterally for a total volume of $1 \mu \mathrm{l}$ for all subjects. The infusion cannula was left in position for $4 \mathrm{~min}$ following completion of infusion to allow for diffusion of the APV or aCSF. The infusion cannula was replaced with a dummy 
cannula and subjects were subsequently transferred to an experimental room to undergo trace fear conditioning. Subjects were killed $1 \mathrm{~h}$ after conditioning for Western blot analysis of Arc protein in $\mathrm{DH}$ and $\mathrm{VH}$.

\section{Histology}

To verify cannula placement in subjects tested in behavioral experiments following infusions of Arc antisense ODNs, animals were administered a sublethal dose of sodium pentobarbital (100 mg/kg, i.p.) and perfused transcardially with $0.9 \%$ saline followed by buffered $10 \%$ formalin. The brain was removed and placed in a 10\% formalin-30\% sucrose solution for at least $3 \mathrm{~d}$. The brain was then frozen and sliced into coronal sections with a thickness of $50 \mu \mathrm{m}$ using a cryostat. Every other slice throughout the $\mathrm{DH}$ or $\mathrm{VH}$ was mounted on gelled glass microscope slides and subsequently stained with cresyl violet and coverslipped. An observer blind to the subject's condition verified cannula placement throughout the DH or VH. Subjects with inaccurate cannula placement or extensive damage were excluded from data analysis.

\section{Quantitative real-time PCR}

Subjects were handled $2 \mathrm{~min}$ per day for $5 \mathrm{~d}$ before behavioral testing. They were then trained in the trace, contextual, or delay fear conditioning paradigms described above and killed $15 \mathrm{~min}$ after the end of training (Fig. 1c). Separate subjects serving as untrained control subjects were removed from their home cage and killed without undergoing any behavioral training. For all subjects, the brain was removed after rapid decapitation. The hippocampus was extracted, placed on a freezing aluminum dissection stage, and bisected midway between the septal and temporal poles; the $\mathrm{DH}$ comprised the septal half and the $\mathrm{VH}$ comprised the temporal half. Samples were flash-frozen in liquid nitrogen and stored at $-80^{\circ} \mathrm{C}$ until processed.

Total RNA was isolated using a Promega SV Total RNA Isolating System, and RNA was purified using the RNeasy Mini Kit (Qiagen). Absorbance values for the samples were determined using a NanoDrop ND-1000 spectrophotometer. RNA concentration was determined using UV absorption at $260 \mathrm{~nm}$. RNA purity was assessed using the ratio of absorbance at $260 / 280 \mathrm{~nm}$ and $260 / 230 \mathrm{~nm}$. Samples that did not have an absorbancy ratio between 1.8 and 2.15 were removed from further analysis. Total RNA $(1 \mu \mathrm{l})$ was reverse transcribed using an iScript cDNA Synthesis Kit (Bio-Rad) to a total volume of $67.5 \mu \mathrm{l}$ and stored at $-20^{\circ} \mathrm{C}$ after the reaction was complete. Quantitative real-time PCR was performed in a 7900HT Real-Time PCR System (Applied Biosystems) using the SYBR Green Master Mix (Bio-Rad). The primers used were for Arc (forward, CCCTGCAGCCCAAGTTCAAG; reverse, GAAGGCTCAGCTGCCTGCTC) and GAPDH (forward, GCATCCTGCACCACCAACTG, reverse, ACGCCACAGCTTTCCAGAGG). Each sample was run in triplicate per gene of interest. The samples were run at $50^{\circ} \mathrm{C}$ for $4 \mathrm{~min}$ and $95^{\circ} \mathrm{C}$ for $10 \mathrm{~min}$, followed by 40 cycles of $95^{\circ} \mathrm{C}$ for $15 \mathrm{~s}$ and $60^{\circ} \mathrm{C}$ for $1 \mathrm{~min}$.

Relative quantification of Arc mRNA was determined using the $\Delta \Delta C_{\mathrm{T}}$ method described in detail by Livak and Schmittgen (2001). Briefly, the triplicate values of threshold cycle $\left(C_{\mathrm{T}}\right.$, cycle at which sample reached the threshold fluorescence level) for each sample were averaged. Mean $C_{\mathrm{T}}$ values for GAPDH, the endogenous control, were subtracted from mean $C_{\mathrm{T}}$ values of Arc for each subject. This served as the $\Delta C_{\mathrm{T}}$. The subject with the highest $\Delta C_{\mathrm{T}}$ from the home cage untrained control group served as the calibrator and was subtracted from the $\Delta C_{\mathrm{T}}$ of the remaining subjects $\left(\Delta \Delta C_{\mathrm{T}}\right)$. The fold change in the expression of Arc, normalized to the endogenous control $(\mathrm{GAPDH})$, was then determined using the formula $2^{-\Delta \Delta C_{\mathrm{T}}}$. The fold change values were then averaged for each of the respective groups (i.e., $\mathrm{DH}$ trained, $\mathrm{DH}$ untrained, $\mathrm{VH}$ trained, and $\mathrm{VH}$ untrained).

\section{Western blotting}

Subjects were infused with Arc antisense or scrambled ODNs and then underwent trace fear conditioning as described above. A subset of these subjects was killed $1 \mathrm{~h}$ after conditioning (Fig. 1c). Separate subjects serving as untrained control subjects were removed from their home cage and killed without undergoing any training. For all subjects, the brain was removed after rapid decapitation. The hippocampus was removed and dissected into $\mathrm{DH}$ and $\mathrm{VH}$, which were then homogenized in ice-cold $1 \%$ lysis buffer with EDTA/Protease Inhibitor Cocktail (Thermo Scientific) and agitated for $2 \mathrm{~h}$ at $4^{\circ} \mathrm{C}$, followed by $20 \mathrm{~min}$ in the centrifuge at $12,000 \mathrm{rpm}$ at $4^{\circ} \mathrm{C}$.
Protein concentration for each sample was assessed and normalized using a standard Bradford assay. The samples were then loaded into 12\% MiniPROTEAN TGX Precast Gels (Bio-Rad) for gel electrophoresis and then transferred to a nitrocellulose membrane (Ready-Blot sandwiches, Bio$\mathrm{Rad})$. The membrane was then blocked in TBST buffer with 5\% BSA for $1.5 \mathrm{~h}$ at room temperature. Following blocking, the membrane was incubated with mouse anti-Arc monoclonal antibody (1:5000; Santa Cruz Biotechnology) and rabbit anti-actin polyclonal antibody (1:20,000; Sigma-Aldrich) overnight at $4^{\circ} \mathrm{C}$. After incubating in the primary antibody, the membrane was washed 3 times for $15 \mathrm{~min}$ at room temperature in TBST solution before being incubated in both anti-rabbit and anti-mouse conjugated to horseradish peroxidase (1:10,000; Santa Cruz Biotechnology) for $1 \mathrm{~h}$ at room temperature. The blots were developed using chemiluminescent substrate ECL reagent (Pierce) according to the manufacturer's instructions and imaged with a Fluor-S Scanner (Bio-Rad), and normalized to actin for each sample. Data for subjects that received ODN infusions and were trained in trace fear conditioning are expressed as a percentage increase in optical density compared with home cage untrained control subjects.

\section{Results}

Trace and contextual, but not delay, fear conditioning enhances Arc mRNA expression in $\mathrm{DH}$ and $\mathrm{VH}$

Quantitative real-time PCR was performed on the subjects receiving 10 training trials with a 4 min ITI in trace, contextual, or delay conditioning. Note that delay conditioning procedures followed a $24 \mathrm{~h}$ period of preexposure to the training chamber to reduce the salience of the context. Our results suggest that both trace and contextual fear conditioning resulted in a significant increase in levels of Arc mRNA in both DH (Fig. 1a) and VH (Fig. $1 b$ ) relative to home-cage control animals, while delay conditioning did not. A two-way ANOVA revealed that there was a significant difference between training conditions $\left(F_{(3,62)}=19.45, p<\right.$ $0.001)$ and brain region $\left(F_{(3,63)}=6.17, p<0.05\right)$, but not an interaction between brain region and training $\left(F_{(3,62)}=1.57, p>\right.$ $0.05)$. Student-Newman-Keuls (SNK) post hoc analyses showed that Arc mRNA levels of animals trained in trace (DH, $n=12$; $\mathrm{VH}, n=9$ ) and contextual ( $\mathrm{DH}, n=6 ; \mathrm{VH}, n=8)$ conditioning were significantly enhanced relative to those trained in delay conditioning ( $\mathrm{DH}, n=5 ; \mathrm{VH}, n=5)$ and home-cage control animals ( $\mathrm{DH}, n=9$; VH, $n=9$ ), with higher overall Arc mRNA levels in $\mathrm{DH}$ compared with $\mathrm{VH}$ (all $p$ values $<0.05$ ).

A similar pattern of effects was observed in animals trained on the more temporally precise version of trace conditioning in which the number of trials was reduced to 7 and the ITI was reduced to $2 \mathrm{~min}$ (Fig. $1 d$ ). A two-way ANOVA revealed a significant difference between trained and untrained subjects $\left(F_{(1,23)}=\right.$ $12.79, p<0.01)$. There was no significant effect for brain region $\left(F_{(1,23)}=0.39, p>0.05\right)$, nor was there an interaction between training condition and region $\left(F_{(1,23)}=0.17, p>0.05\right)$, indicating there was a significant increase in Arc mRNA in trained compared with untrained subjects in both $\mathrm{DH}$ (trained, $n=7$; untrained, $n=7$ ) and $\mathrm{VH}$ (trained $=5$; untrained $=5$ ).

\section{Trace fear conditioning enhances Arc protein expression in $\mathrm{DH}$ and $\mathrm{VH}$, which is blocked by Arc ODN infusion}

We used Western blots to assess levels of Arc protein expression in $\mathrm{DH}$ and $\mathrm{VH}$ following pretraining infusions of Arc antisense or scrambled ODNs. Representative Western blots showing Arc and actin bands for subjects with cannulae implanted into $\mathrm{DH}$ or $\mathrm{VH}$, as well as the mean $( \pm$ SEM) percentage increase in Arc protein expression relative to actin and naive controls $(n=5)$ are depicted in Figure $1 e-h$. For subjects receiving infusions of scrambled $(n=4)$ or Arc antisense $(n=5)$ ODNs into DH before trace fear conditioning, a two-way ANOVA with brain region and in- 


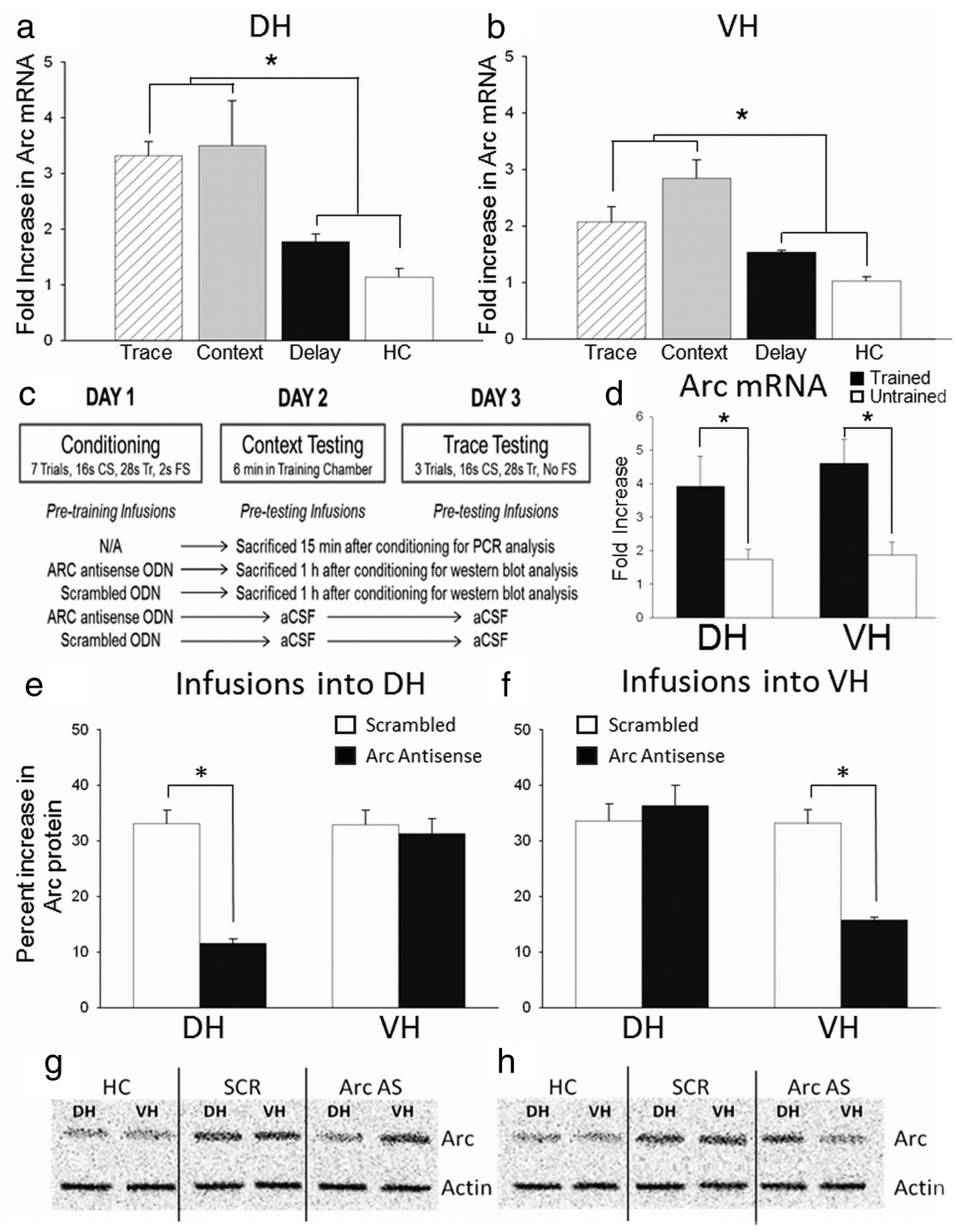

Figure 1. $\quad \boldsymbol{a}, \boldsymbol{b}$, Mean ( \pm SEM) fold change in Arc mRNA relative to both untrained home cage controls and GAPDH. There was a significant increase in Arc mRNA expression in DH (a) and VH (b) after trace and contextual, but not delay, fear conditioning. ${ }^{*} p<$ 0.05. c, Experiment design. $d$, Mean ( \pm SEM) fold change in Arc mRNA relative to both untrained home cage controls and GAPDH. Trace fear conditioning enhanced Arc mRNA levels in DH and VH. ${ }^{*} p<0.05 . e, f$, Mean ( \pm SEM) percentage increase in Arc protein expression relative to untrained home cage controls and actin. Infusions of Arc antisense 0DNs into DH $(\boldsymbol{e})$ or VH $(\boldsymbol{f})$ attenuated the learning-induced enhancement of Arc protein in a regionally specific manner. ${ }^{*} p<0.05 . \boldsymbol{g}, \boldsymbol{h}$, Representative blots for subjects with cannula targeted at DH $(\boldsymbol{g})$ or VH $(\boldsymbol{h})$. HC, Home cage controls; SCR, scrambled ODN infusion; AS, Arc antisense ODN infusion.

$\left(F_{(1,17)}=10.40, p<0.01\right)$. There was also a significant interaction between brain region and infusion condition $\left(F_{(1,17)}=\right.$ 13.40, $p<0.01)$. Subsequent post hoc analyses revealed that Arc antisense ODN infusions in $\mathrm{VH}$ significantly and selectively attenuated Arc protein levels in the VH only ( $p<0.05$; SNK) (Fig. $1 f)$. Thus, just as with $\mathrm{DH}$, trace conditioning enhances Arc protein expression in $\mathrm{VH}$, and this learning-related increase in Arc expression is attenuated in a regionally specific manner by pretraining infusion of Arc antisense ODNs into VH.

\section{Pretraining infusion of Arc antisense} ODNs into DH or $\mathrm{VH}$ impairs the consolidation of trace and contextual fear conditioning

The findings from our behavioral experiments examining the effect of Arc antisense infusion on the acquisition and subsequent expression of contextual and trace fear conditioning are depicted in Figure 2. Subjects received infusions of Arc antisense or scrambled ODNs into $\mathrm{DH}$ or VH $3 \mathrm{~h}$ before trace fear conditioning and were subsequently tested $48 \mathrm{~h}$ later. In addition, we examined conditioned freezing to the context $24 \mathrm{~h}$ after conditioning. Histological verification was conducted for all subjects undergoing behavioral testing. A representative photomicrograph depicting accurate cannula placement in $\mathrm{DH}$ and $\mathrm{VH}$ is shown in Figure $2, h$ and $i$. Only subjects whose cannula tips were confined within DH (Fig. $2 h$ ) or VH (Fig. 2i) were included for statistical analysis. Data were analyzed using separate two-way ANOVAs for the different time intervals during conditioning and testing with brain region and infusion condition as main factors.

The mean $( \pm$ SEM) percentage of freezing exhibited during the conditioning session is shown in Figure $2 a-c$. There were no significant differences in freezing

fusion condition as the main factors revealed there was a significant main effect for brain region $\left(F_{(1,17)}=19.00, p<0.01\right)$ and for infusion condition $\left(F_{(1,17)}=26.90, p<0.01\right)$. There was also a significant interaction between brain region and infusion condition $\left(F_{(1,17)}=19.80, p<0.01\right)$. Subsequent post hoc analyses revealed that Arc antisense ODN infusions in $\mathrm{DH}$ significantly and selectively attenuated Arc protein levels in the DH only $(p<$ 0.05; SNK) (Fig. 1e). Thus, trace fear conditioning enhances Arc expression in $\mathrm{DH}$, and this learning-related increase in Arc expression is attenuated in a regionally selective manner by pretraining infusion of Arc antisense ODNs into DH.

For subjects receiving infusions of scrambled $(n=4)$ or Arc antisense $(n=5)$ ODNs into VH before trace fear conditioning, a two-way ANOVA with brain region and infusion condition as the main factors revealed there was a significant main effect for brain region $\left(F_{(1,17)}=9.41, p<0.01\right)$ and for infusion condition during trial 1 (baseline) of the ITI (region, $F_{(1,35)}=1.40, p>0.05$; condition, $F_{(1,35)}=1.32, p>0.05$; region $\times$ condition, $F_{(1,35)}=$ $1.37, p>0.05$ ), CS (region, $F_{(1,35)}=0.16, p>0.05$; condition, $F_{(1,35)}=0.16, p>0.05$, region $\times$ condition, $F_{(1,35)}=1.80, p>$ 0.05 ), or trace interval (region, $F_{(1,35)}=0.90, p>0.05$, condition: $F_{(1,35)}=0.59, p>0.05$, region $\times$ condition, $F_{(1,35)}=0.001, p>$ $0.05)$. Although overall freezing increased after the first US presentation at the end of trial 1 , groups did not differ in freezing behavior during trials $2-7$ of the ITI (region, $F_{(1,35)}=0.10, p>$ 0.05 ; condition, $F_{(1,35)}=0.87, p>0.05$, region $\times$ condition, $F_{(1,35)}=0.006, p>0.05$ ), CS (region, $F_{(1,35)}=0.94, p>0.05$; condition, $F_{(1,35)}=1.17, p>0.05$, region $\times$ condition, $F_{(1,35)}=$ $0.31, p>0.05$ ), or trace interval (region, $F_{(1,35)}=0.15, p>0.05$; condition, $F_{(1,35)}=0.32, p>0.05$; region $\times$ condition, $F_{(1,35)}=$ $0.02, p>0.05)$, suggesting that all subjects successfully acquired trace fear conditioning regardless of the infusion condition or 
targeted subregion. Furthermore, these data strongly suggest that the Arc antisense ODNs did not alter footshock sensitivity, sensory processing, or freezing behavior during conditioning.

The mean $( \pm \mathrm{SEM})$ percentage of freezing exhibited during the testing session for trace fear conditioning is shown in Figure $2 d-f$. There was no main effect for infusion condition $\left(F_{(1,35)}=2.12, p>\right.$ 0.05 ) during trial 1 of the ITI (baseline), but there was a main effect for brain region $\left(F_{(1,35)}=4.42, p=0.04\right.$. SNK post hoc analyses revealed that subjects with cannula in $\mathrm{VH}$ froze slightly more during baseline than those with cannula in $\mathrm{DH}$. During trials 2-3 of the ITI, there was a significant difference between infusion condition $\left(F_{(1,35)}=30.46, p<0.001\right)$, but there was no main effect for brain region $\left(F_{(1,35)}=0.17, p>0.05\right)$ or an interaction between brain region and infusion condition $\left(F_{(1,35)}=0.02, p>0.05\right)$. This same pattern was observed during the CS (region, $F_{(1,35)}=19.52, p<0.001$; condition, $F_{(1,35)}=1.70, p>0.05$; interaction, $F_{(1,35)}$ $=0.14, p>0.05)$ and trace interval (region, $F_{(1,35)}=36.45, p<0.001$; condition, $F_{(1,35)}=0.01, p>0.05$; interaction, $F_{(1,35)}$ $=0.02, p>0.05)$. SNK post hoc analyses revealed that subjects that received infusions of Arc antisense ODNs (DH, $n=9$; $\mathrm{VH}, n=11$ ) exhibited significantly less freezing than those that received scrambled ODNs (DH, $n=9$; VH, $n=7$ ) during the ITI, CS, and trace interval of the testing session $(p<0.05)$, regardless of whether the infusions were into $\mathrm{DH}$ or VH. These data indicate that blocking protein translation with Arc antisense ODNs in either DH or VH before training attenuated the expression of trace fear conditioning $48 \mathrm{~h}$ after training, and are consistent with the view that Arcmediated plasticity may underlie the consolidation of some forms of memory (Bramham et al., 2010).

The mean ( \pm SEM) percentage of freezing during the 6 min context test is shown in Figure $2 g$. There was a main effect for infusion condition $\left(F_{(1,35)}=21.58, p<0.001\right)$, but no main effect for region $\left(F_{(1,35)}=1.83, p>0.05\right)$ or an interaction between brain region and infusion condition $\left(F_{(1,35)}=0.02, p>0.05\right)$. SNK post hoc analyses revealed that subjects that received Arc antisense ODNs (DH, $n=9$; $\mathrm{VH}, n=11$ ) froze significantly less during context testing compared with those that received the scrambled ODNs ( $\mathrm{DH}, n=9$; $\mathrm{VH}, n=$ 7) regardless of what brain region was infused. These data suggest that blocking Arc translation in $\mathrm{DH}$ or $\mathrm{VH}$ before training impairs contextual, as well as trace, fear conditioning.

\section{Pretraining infusion of Arc antisense ODNs into $\mathrm{VH}$ has no effect on the acquisition or retention of delay fear conditioning}

The expression of conditioned fear exhibited during the conditioning and testing sessions for subjects receiving Arc antisense
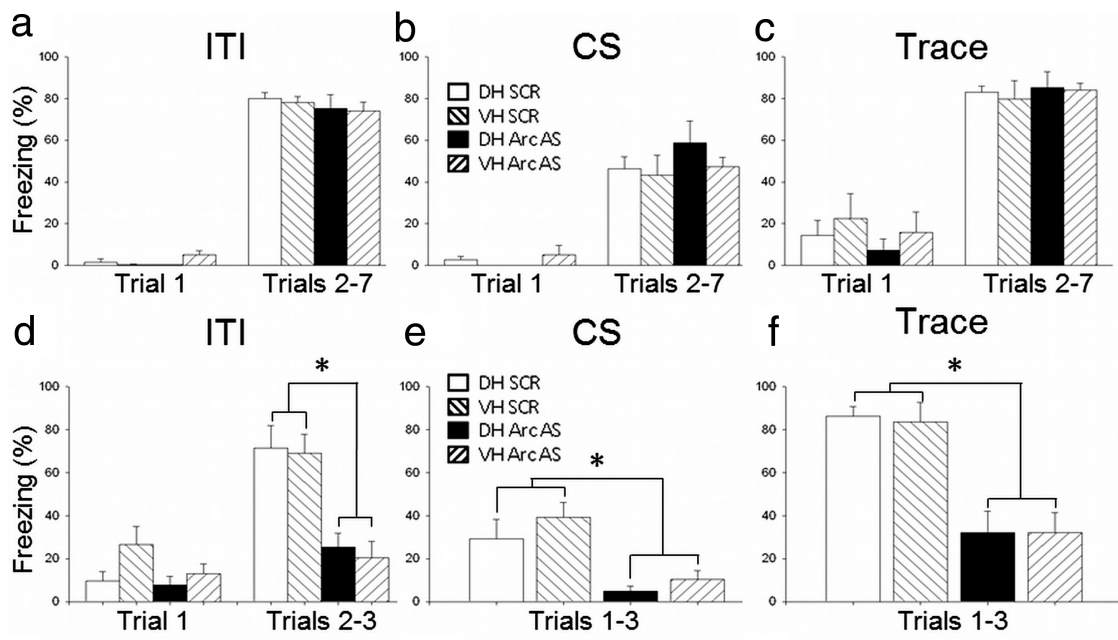

i
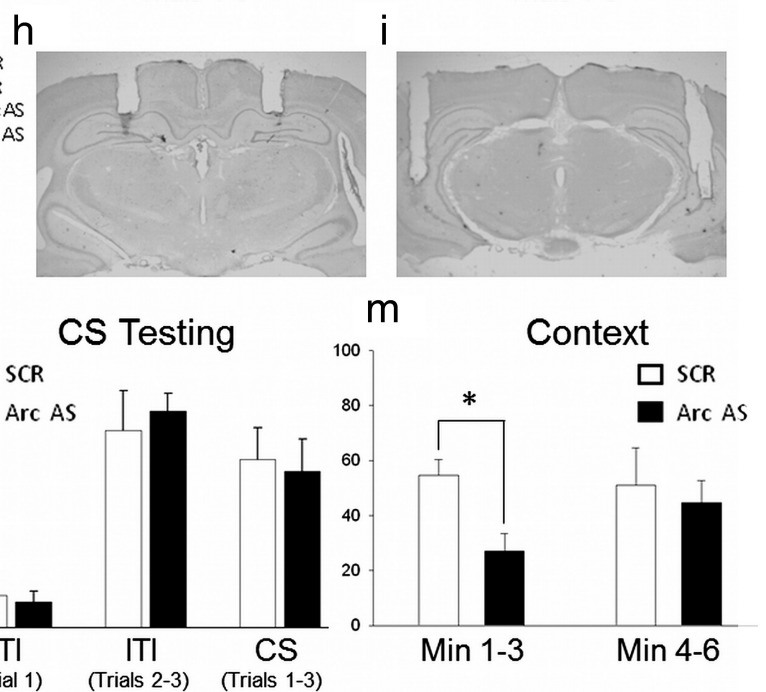

Figure 2. $\boldsymbol{a}-\boldsymbol{c}$, Mean ( \pm SEM) percentage freezing during training in the trace conditioning paradigm. Infusions of Arc antisense or scrambled ODNs into the DH or VH had no effect on behavior during the ITI (a), CS (b) or the trace interval (c). $\boldsymbol{d}$-f, Mean tisense ODNs into DH or VH impaired conditioned freezing during the context test. ${ }^{*} p<0.05 . \boldsymbol{h}, \boldsymbol{i}$, Representative photomicro列 conditioning had no effect on freezing to the $C S$ during subsequent testing $(I)$, but significantly impaired conditioned freezing during the first 3 min of the context test $(\boldsymbol{m}) .{ }^{*} p<0.05$. SCR, Scrambled ODN infusion; Arc AS, Arc antisense ODN infusion.

$(n=9)$ or scrambled ODN $(n=7)$ infusions into VH before delay fear conditioning is depicted in Figure $2 j-l$. For conditioning, a $t$ test revealed that there was no significant difference in freezing between the two groups during the first trial (baseline) of the ITI $\left(t_{(1,14)}=0.18, p>0.05\right)$ or $\operatorname{CS}\left(t_{(1,14)}=0.64, p>0.05\right)$, nor was there a significant difference during trials $2-7$ of the ITI $\left(t_{(1,14)}=1.13, p>0.05\right)$, or CS presentations $\left(t_{(1,14)}=0.37, p>\right.$ $0.05)$. For testing, a $t$ test revealed there was no significant difference in freezing between the two groups during the first trial (baseline) of the ITI $\left(t_{(1,14)}=0.40, p>0.05\right)$, nor was there a significant difference during trials $2-3$ of the ITI $\left(t_{(1,14)}=0.49\right.$, $p>0.05)$, or during the CS presentations $\left(t_{(1,14)}=0.26, p>\right.$ $0.05)$. Thus, unlike trace fear conditioning, delay fear conditioning is unaffected by infusion of Arc antisense ODNs into $\mathrm{VH}$.

The mean $( \pm$ SEM) percentage of freezing during the context test is shown in Figure $2 m$. A $t$ test revealed that subjects with Arc antisense ODN infusions into $\mathrm{VH}$ before conditioning froze significantly less during the first $3 \min \left(t_{(1,14)}=3.10, p<0.01\right)$ but 

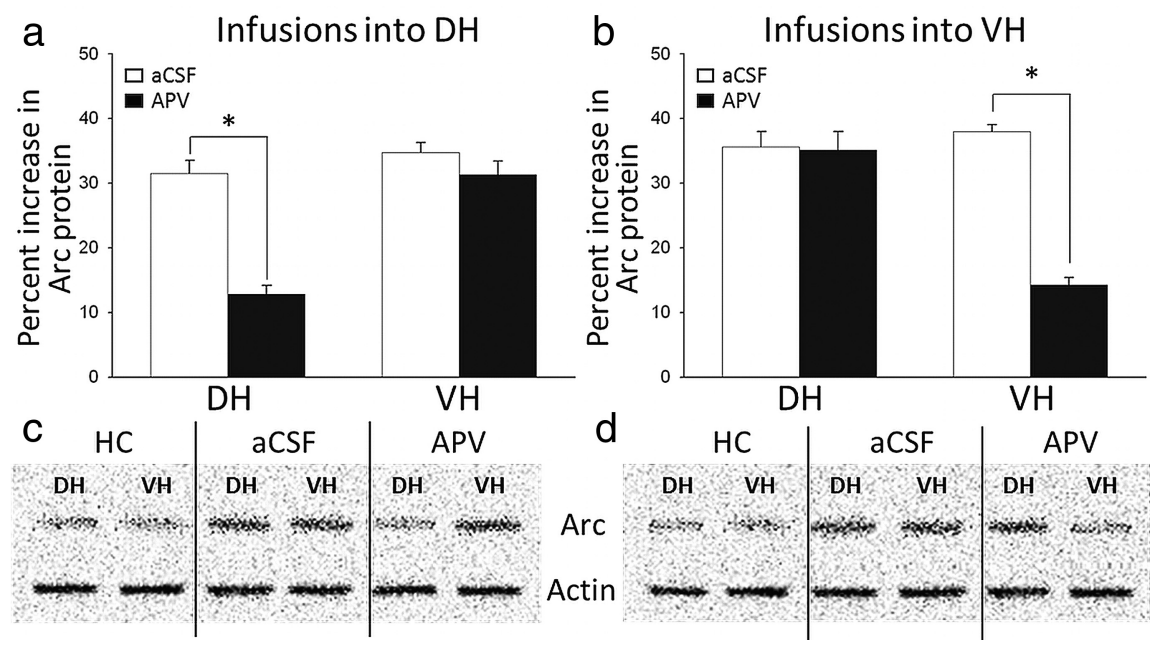

Figure 3. $\boldsymbol{a}, \boldsymbol{b}$, Mean $( \pm S E M)$ percentage increase in Arc protein expression relative to untrained home cage controls and actin Infusions of APV into DH (a) or VH $(\boldsymbol{b})$ attenuated the learning-induced enhancement of Arc protein in a regionally specific manner. ${ }^{*} p<0.05$. $\boldsymbol{c}, \boldsymbol{d}$, Representative blots for subjects with cannula targeted at DH (c) or VH (d). HC, Home cage controls.

not the last $3 \mathrm{~min}$ of the context test $\left(t_{(1,14)}=0.41, p>0.05\right)$ compared with those that received the scrambled ODN infusions. The robust difference in the first several minutes of the context test suggests that pretraining Arc antisense ODN infusions into VH significantly attenuated contextual fear conditioning while leaving the acquisition of delay fear conditioning in the same animals unaffected.

\section{Pretraining infusion of the NMDA receptor antagonist APV into $\mathrm{DH}$ or $\mathrm{VH}$ blocks the learning-induced enhancement of Arc protein in a regionally selective manner}

To determine whether the learning-induced increase in Arc is NMDA receptor dependent, we infused APV into $\mathrm{DH}$ or $\mathrm{VH}$ before trace fear conditioning and subsequently performed Western blots to measure Arc protein levels in both regions after training. The mean $( \pm$ SEM) percentage increase in Arc protein expression compared with actin and relative to home cage controls $(n=6)$ is shown in Figure 3. For subjects receiving infusions of APV $(n=8)$ or aCSF $(n=8)$ into DH before trace fear conditioning, a two-way ANOVA with brain region and infusion condition as the main factors revealed there was a significant main effect for brain region $\left(F_{(1,31)}=38.90, p<0.001\right)$ and for infusion condition $\left(F_{(1,31)}=39.7, p<0.001\right)$. There was also a significant interaction between brain region and infusion condition $\left(F_{(1,31)}=18.9, p<0.001\right)$. Subsequent post hoc analyses revealed that pretraining infusions of APV into DH significantly and selectively attenuated the level of training-induced Arc protein in DH only $(p<0.05$; Fig. $3 a)$. A representative blot depicting Arc and actin bands for subjects receiving infusions into $\mathrm{DH}$ is depicted in Figure $3 c$.

For subjects receiving infusions of APV $(n=8)$ or aCSF $(n=$ 8) into $\mathrm{VH}$ before trace fear conditioning, a two-way ANOVA with brain region and infusion condition as the main factors revealed there was a significant main effect for brain region $\left(F_{(1,31)}=20.9, p<0.001\right)$ and for infusion condition $\left(F_{(1,31)}=\right.$ $36.2, p=<0.001)$. There was also a significant interaction between brain region and infusion condition $\left(F_{(1,31)}=33.2, p<\right.$ $0.001)$. Subsequent post hoc analyses revealed that pretraining infusion of APV into VH significantly and selectively attenuated the level of training-induced Arc protein in VH only $(p<0.05$;
Fig. 3b). A representative blot depicting Arc and actin bands for subjects receiving infusions into $\mathrm{VH}$ is depicted in Figure $3 d$.

\section{Discussion}

The expression of Arc in DH and $\mathrm{VH}$ is enhanced following trace and contextual, but not delay, fear conditioning

We observed enhanced Arc mRNA expression in both $\mathrm{DH}$ and $\mathrm{VH}$ following trace and contextual, but not delay, fear conditioning. This is consistent with other reports demonstrating behaviorally dependent enhancements of Arc transcription in the hippocampus (Guzowski et al., 1999; Kelly and Deadwyler, 2002; Montag-Sallaz and Montag, 2003; Fletcher et al., 2006; Huff et al., 2006). Importantly, there was no increase in Arc mRNA in subjects trained in a delay paradigm following prolonged $(24 \mathrm{~h})$ context preexposure, suggesting that the enhancement of Arc mRNA observed in animals receiving either trace or contextual conditioning is not attributable to the delivery of footshock or the novelty of tone exposures alone. This upregulation of Arc mRNA was observed in both DH and $\mathrm{VH}$, further supporting the notion that both subregions normally participate in the acquisition and maintenance of memory for trace and contextual fear conditioning.

Consistent with the learning-related upregulation of Arc mRNA expression, we also observed an enhancement of Arc protein expression in both $\mathrm{DH}$ and $\mathrm{VH}$ following trace fear conditioning. Although an increase in Arc protein in the hippocampus following delay fear conditioning has been reported previously (Lonergan et al., 2010), our mRNA data suggest that this enhancement may be attributed to context learning that typically accompanies delay conditioning, and not delay conditioning itself. Collectively, these data suggest that Arc transcription and translation in the hippocampus are likely regulated, at least in part, by training in tasks that are hippocampus dependent.

\section{Arc antisense ODNs impair both trace and contextual fear} conditioning and the corresponding learning-related increase in Arc protein expression

To further explore the relationship between Arc expression and hippocampus-dependent learning, we examined the effect of blocking Arc translation on trace and contextual fear conditioning. Pretraining infusions of Arc antisense ODNs into either DH or VH had no effect on behavior during training, but dramatically attenuated the expression of trace and contextual fear conditioning during subsequent testing. It is difficult to determine whether the observed deficits reflect actual impairments of acquisition, consolidation, or both. However, the patterns of data reported here are consistent with those suggesting an important role for Arc in the maintenance of late-phase LTP and the consolidation of some forms of memory (Guzowski et al., 2000; McIntyre et al., 2005; Plath et al., 2006; Ploski et al., 2008).

Arc antisense ODNs also blocked the learning-related increase in Arc protein expression in the targeted subregions. Importantly, the effect of ODNs was regionally selective: there was no difference in Arc protein levels in DH for subjects infused with Arc antisense or scrambled ODNs into VH, and vice versa. More- 
over, there was a remarkably consistent increase in Arc protein expression after scrambled ODN infusions and in the noncannulated hippocampal subregion, indicating that the spread of infusion was confined to the targeted subregion and that there were no adverse effects of cannula implantation or infusion of scrambled ODNs on the learning-induced enhancement of Arc protein.

This study is the first to use ODNs to selectively target distinct subregions of the hippocampus, and our data suggest that downstream molecular cascades involving Arc in both $\mathrm{DH}$ and $\mathrm{VH}$ are required for lasting memory of trace and contextual fear conditioning. These data appear to conflict with those of several reports demonstrating a functional dissociation between $\mathrm{DH}$ and $\mathrm{VH}$ (Bannerman et al., 1999; Richmond et al., 1999). Specifically, we have previously demonstrated that both lesions and temporary inactivation of $\mathrm{VH}$, but not $\mathrm{DH}$, before training impair the acquisition of trace fear conditioning (Yoon and Otto, 2007; Czerniawski et al., 2009). By contrast, pretraining NMDA receptor antagonism or post-training lesions of either DH dramatically impair the expression of trace fear conditioning (Misane et al., 2005; Quinn et al., 2005; Wanisch et al., 2005; Yoon and Otto, 2007). Together with our current findings, these data suggest that while $\mathrm{DH}$ integrity may not be critical to the acquisition of trace fear conditioning, learning-related plasticity within both $\mathrm{DH}$ and $\mathrm{VH}$ may normally be involved in forming or maintaining associations in trace and contextual conditioning if those regions are intact during learning, and that this learning-induced plasticity is likely required for the consolidation or subsequent recall of memory in these paradigms.

The results of the present study suggest that Arc-mediated plasticity within both $\mathrm{DH}$ and VH likely underlie the consolidation of memory for contextual and trace fear conditioning. However, consistent with the general view that the hippocampus is not necessary to learn delay fear conditioning (Phillips and LeDoux, 1992; McEchron et al., 1998), blocking Arc translation in VH did not block the formation of, or memory for, CS-US associations in delay fear conditioning. Furthermore, the previously described pattern of effects cannot be attributed to diffusion of the antisense ODNs into the amygdala, which has been shown to result in a robust impairment of fear conditioning (Ploski et al., 2008). Although there have been a few reports suggesting that VH may participate in some aspects of delay fear conditioning (Bast et al., 2001; Maren and Holt, 2004), the present data suggest that Arc protein translation is not a necessary component of $\mathrm{VH}$ involvement in delay fear conditioning. While administration of Arc antisense ODNs into $\mathrm{VH}$ did not alter freezing levels during testing, it robustly attenuated freezing during the first 3 min of the context test. Additionally, because all animals exhibited robust freezing behavior to the explicit CS during testing, it is highly unlikely that any observed behavioral deficits in freezing are due to possible effects of the ODNs on locomotor activity and/or sensory processing during acquisition. This dissociation provides compelling evidence suggesting that Arc translation in the hippocampus is essential for memory formation of trace and contextual, but not delay, fear conditioning.

\section{The learning-related increase in Arc expression is dependent on NMDA receptor activation}

In vitro, activity-dependent Arc expression is blocked by NMDA receptor antagonism (Link et al., 1995; Lyford et al., 1995; Steward et al., 1998). We now demonstrate that NMDA receptor antagonism has a similar effect in vivo, and further that Arc expression and the induction of LTP may have a partially overlapping, common underlying chemistry. Interestingly, the main- tenance and consolidation of LTP itself requires sustained Arc expression (Guzowski et al., 2001; Messaoudi et al., 2007). In addition to the expression of Arc, the selective targeting of Arc to recently active synapses is also dependent on NMDA receptor activation (Steward and Worley, 2001). Together with the now well established finding that both trace and contextual conditioning are blocked by intrahippocampal infusion of the NMDA receptor antagonist APV (Misane et al., 2005; Quinn et al., 2005; Wanisch et al., 2005; Czerniawski et al., 2010), these data strongly suggest that NMDA receptor activation and Arc expression may be interdependent processes working in tandem to support experience-dependent alterations in synaptic strength that underlie long-term memory formation.

\section{Summary}

Our study adds to the converging data supporting the notion that Arc may play a particularly prominent role in the acquisition and maintenance of a variety of types of learning (Guzowski et al., 2001; McIntyre et al., 2005; Ploski et al., 2008). Based largely on work examining the relationship between Arc expression and synaptic plasticity in vitro, Bramham et al. (2010) have suggested that Arc is likely a key regulator of protein synthesis-dependent neuronal plasticity and, ultimately, memory (see also Shepherd and Bear, 2011). Specifically, Arc has been implicated in the stabilization of LTP, LTD, and homeostatic plasticity (Bramham et al., 2010), and likely contributes to modifying synaptic strength through effects on postsynaptic density (Messaoudi et al., 2007). Arc is also involved in AMPA receptor endocytosis (Chowdhury et al., 2006; Rial Verde et al., 2006; Waung et al., 2008), indicating that Arc may play a role in homeostatic scaling, in which a reduction of AMPA receptors leads to a weakening of excitatory signaling without changing the relative strengths of the inputs (Turrigiano, 2008). A precise characterization of the specific combination of these mechanisms that may be implemented in vivo during or as a result of learning awaits further study.

In the current study we demonstrate that the transcription and translation of Arc in DH and VH is regulated by hippocampusdependent but not hippocampus-independent forms of learning. Moreover, blocking Arc translation blocks the learning-induced enhancement of Arc protein in both $\mathrm{DH}$ and $\mathrm{VH}$, as well as memory formation in trace and contextual fear conditioning. Finally, we demonstrate that the learning-induced enhancement of Arc protein is dramatically attenuated by NMDA receptor antagonism, suggesting that these processes appear to be tightly coupled and likely interdependent. Collectively, our data provide compelling support for the notion that NMDA receptor-mediated expression of Arc may underlie the acquisition of a variety of forms of learning that may be differentially dependent on $\mathrm{DH}$ and $\mathrm{VH}$.

\section{References}

Bannerman DM, Yee BK, Good MA, Heupel MJ, Iversen SD, Rawlins JN (1999) Double dissociation of function within the hippocampus: a comparison of dorsal, ventral, and complete hippocampal cytotoxic lesions. Behav Neurosci 113:1170-1188.

Bast T, Zhang WN, Feldon J (2001) The ventral hippocampus and fear conditioning in rats: Different anterograde amnesias of fear after tetrodotoxin inactivation and infusion of the GABAa agonist muscimol. Exp Brain Res 139:39-52.

Bliss T, Collingridge G, Morris R (2007) Synaptic plasticity in the hippocampus. In: The hippocampus book (Andersen P, Morris R, Amaral D, Bliss T, O'Keefe J, eds), pp 343-474. New York: Oxford UP.

Bramham CR, Alme MN, Bittins M, Kuipers SD, Nair RR, Pai B, Panja D, Schubert M, Soule J, Tiron A, Wibrand K (2010) The Arc of synaptic memory. Exp Brain Res 200:125-140.

Chowdhury S, Shepherd JD, Okuno H, Lyford G, Petralia RS, Plath N, Kuhl D, 
Huganir RL, Worley PF (2006) Arc/Arg3.1 interacts with the endocytic machinery to regulate AMPA receptor trafficking. Neuron 52:445-459.

Czerniawski J, Yoon T, Otto T (2009) Dissociating space and trace in dorsal and ventral hippocampus. Hippocampus 19:20-32.

Czerniawski J, Ree F, Chia C, Ramamoorthi K, Otto T (2010) The Arc of trace fear conditioning. Soc Neurosci Abstr 36:735.4

Fletcher BR, Calhoun ME, Rapp PR, Shapiro ML (2006) Fornix lesions decouple the induction of hippocampal Arc transcription from behavior but not plasticity. J Neurosci 26:1507-1515.

Guzowski JF (2002) Insights into immediate-early gene function in hippocampal memory consolidation using antisense oligonucleotide and fluorescent imaging approaches. Hippocampus 12:86-104.

Guzowski JF, McNaughton BL, Barnes CA, Worley PF (1999) Environmentspecific expression of the immediate-early gene Arc in hippocampal neuronal ensembles. Nat Neurosci 2:1120-1124.

Guzowski JF, Lyford GL, Stevenson GD, Houston FP, McGaugh JL, Worley PF, Barnes CA (2000) Inhibition of activity-dependent Arc protein expression in the rat hippocampus impairs the maintenance of long-term potentiation and consolidation of long-term memory. J Neurosci 20:3993-4001.

Guzowski JF, Setlow B, Wagner EK, McGaugh JL (2001) Experiencedependent gene expression in the rat hippocampus following spatial learning: a comparison of the immediate early genes $A r c, c$-fos, and zif 268 . J Neurosci 21:5089-5098.

Huff NC, Frank M, Wright-Hardesty K, Sprunger D, Matus-Amat P, Higgins E, Rudy JW (2006) Amygdala regulation of immediate-early-gene expression in the hippocampus induced by contextual fear conditioning. J Neurosci 26:1616-1623.

Kelly MP, Deadwyler SA (2002) Acquisition of a novel behavior induces higher levels of Arc mRNA than does overtrained performance. Neuroscience 110:617-626.

Kim JJ, Fanselow MS (1992) Modality-specific retrograde amnesia of fear. Science 256:675-677.

Link W, Konietzko U, Kauselmann G, Krug M, Schwanke B, Frey U, Kuhl D (1995) Somatodendritic expression of an immediate early gene is regulated by synaptic activity. Proc Natl Acad Sci U S A 92:5734-5738.

Livak KJ, Schmittgen TD (2001) Analysis of relative gene expression data using real-time quantitative PCR and the $2^{-\Delta \Delta \mathrm{CT}_{\mathrm{T}}}$ method. Methods 25:402-408.

Lonergan ME, Gafford GM, Jarome TJ, Helmstetter FJ (2010) Timedependent expression of Arc and Zif268 after acquisition of fear conditioning. Neural Plast 2010:139891.

Lyford GL, Yamagata K, Kaufmann WE, Barnes CA, Sanders LK, Copeland NG, Gilbert DJ, Jenkins NA, Lanahan AA, Worley PF (1995) Arc, a growth factor and activity-regulated gene, encodes a novel cytoskeleton-associated protein that is enriched in neuronal dendrites. Neuron 14:433-445.

Maren S, Holt WG (2004) Hippocampus and Pavlovian fear conditioning in rats: muscimol infusions into the ventral but not dorsal, hippocampus impair the acquisition of conditioned freezing to an auditory conditioned stimulus. Behav Neurosci 118:97-110.

McEchron MD, Bouwmeester H, Tseng W, Weiss C, Disterhoft JF (1998) Hippocampectomy disrupts auditory trace fear conditioning in the rat. Hippocampus 8:638-646.

McIntyre CK, Miyashita T, Setlow B, Marjon KD, Steward O, Guzowski JF, McGaugh JL (2005) Memory-influencing intra-basolateral amygdala drug infusions modulate expression of Arc protein in the hippocampus. Proc Natl Acad Sci U S A 102:10718-10723.

Messaoudi E, Kanhema T, Soulé J, Tiron A, Dagyte G, da Silva B, Bramham CR (2007) Sustained Arc/Arg3.1 synthesis controls long-term potentiation consolidation through regulation of local actin polymerization in the dentate gyrus in vivo. J Neurosci 27:10445-10455.

Misane I, Tovote P, Meyer M, Spiess J, Ogren SO, Stiedl O (2005) Time- dependent involvement of the dorsal hippocampus in trace fear conditioning in mice. Hippocampus 15:418-426.

Miyashita T, Kubik S, Lewandowski G, Guzowski JF (2008) Networks of neurons, networks of genes: an integrated view of memory consolidation. Neurobiol Learn Mem 89:269-284.

Montag-Sallaz M, Montag D (2003) Learning-induces Arg3.1/Arc mRNA expression in the mouse brain. Learn Mem 10:99-107.

Moser MB, Moser EI (1998) Functional differentiation in the hippocampus. Hippocampus 8:608-619.

Nakazawa K, McHugh TJ, Wilson MA, Tonegawa S (2004) NMDA receptors, place cells and hippocampal spatial memory. Nat Rev Neurosci 5:361-372.

Phillips RG, LeDoux JE (1992) Differential contributions of amygdala and hippocampus to cued and contextual fear conditioning. Behav Neurosci 106:274-285.

Plath N, Ohana O, Dammermann B, Errington ML, Schmitz D, Gross C, Mao $\mathrm{X}$, Engelsberg A, Mahlke C, Welzl H, Kobalz U, Stawrakakis A, Fernandez E, Waltereit R, Bick-Sander A, Therstappen E, Cooke SF, Blanquet V, Wurst W, Salmen B, et al. (2006) Arc/Arg3.1 is essential for the consolidation of synaptic plasticity and memories. Neuron 52:437-444.

Ploski JE, Pierre VJ, Smucny J, Park K, Monsey MS, Overeem KA, Schafe GE (2008) The activity-regulated cytoskeletal-associated protein (Arc) Arg3.1) is required for memory consolidation of Pavlovian fear conditioning in the lateral amygdala. J Neurosci 28:12383-12395.

Quinn JJ, Loya F, Ma QD, Fanselow MS (2005) Dorsal hippocampus NMDA receptors differentially mediate trace and contextual fear conditioning. Hippocampus 2005:5:665-674.

Rial Verde EM, Lee-Osbourne J, Worley PF, Malinow R, Cline HT (2006) Increased expression of the immediate-early gene arc/arg3.1 reduces AMPA receptor-mediated synaptic transmission. Neuron 52:461-474.

Richmond MA, Yee BK, Pouzet B, Veenman L, Rawlins JN, Feldon J, Bannerman DM (1999) Dissociating context and space within the hippocampus. Effects of complete, dorsal, and ventral excitotoxic lesions on conditioned freezing and spatial learning. Behav Neurosci 113:1189-1203.

Shepherd JD, Bear MF (2011) New views of Arc, a master regulator of synaptic plasticity. Nat Neurosci 14:279-284.

Steward O, Worley PF (2001) Selective targeting of newly synthesized Arc mRNA to active synapses requires NMDA receptor activation. Neuron 30:227-240

Steward O, Wallace CS, Lyford GL, Worley PF (1998) Synaptic activation causes the mRNA for the IEG Arc to localize selectively near activated postsynaptic sites on dendrites. Neuron 21:741-751.

Turrigiano GG (2008) The self-tuning neuron: synaptic scaling of excitatory synapses. Cell 135:422-435.

Vazdarjanova A, Ramirez-Amaya V, Insel N, Plummer TK, Rosi S, Chowdhury S, Mikhael D, Worley PF, Guzowski JF, Barnes CA (2006) Spatial exploration induces Arc, a plasticity-related immediate-early gene, only in calcium/calmodulin-dependent protein kinase II-positive principal excitatory and inhibitory neurons of the rat forebrain. J Comp Neurol 498:317-329.

Wanisch K, Tang J, Mederer A, Wotjak CT (2005) Trace fear conditioning depends on NMDA receptor activation and protein synthesis within the dorsal hippocampus of mice. Behav Brain Res 157:63-69.

Waung MW, Pfeiffer BE, Nosyreva ED, Ronesi JA, Huber KM (2008) Rapid translation of Arc/Arg3.1 selectively mediates mGluR-dependent LTD through persistent increases in AMPAR endocytosis rate. Neuron 59:84-97.

Yoon T, Otto T (2007) Differential contributions of the dorsal and ventral hippocampus in rats to trace fear conditioning. Neurobiol Learn Mem 87:464-475. 